\title{
Barriers to the Growth of Small and Medium Scale Construction Enterprises in Ghana
}

\author{
Simon Ofori Ametepey, Emmanuel Yaw Frempong Jnr, John Edward Cobbina \\ Department of Building Technology, Koforidua Technical University, Koforidua, Ghana \\ Email: simon.ametepey@ktu.edu.gh, oforipmp@gmai.com
}

How to cite this paper: Ametepey, S.O., Jnr, E.Y.F. and Cobbina, J.E. (2022) Barriers to the Growth of Small and Medium Scale Construction Enterprises in Ghana. Open Journal of Civil Engineering, 12, 38-55. https://doi.org/10.4236/ojce.2022.121004

Received: November 25, 2021

Accepted: January 25, 2022

Published: January 28, 2022

Copyright $\odot 2022$ by author(s) and Scientific Research Publishing Inc. This work is licensed under the Creative Commons Attribution International License (CC BY 4.0).

http://creativecommons.org/licenses/by/4.0/

(c) (i) Open Access

\begin{abstract}
The construction industry in most developing economies is dominated heavily by small and medium scale enterprises. These construction enterprises need to thrive in an extremely competitive business environment. Conversely, most of these small and medium scale construction enterprises (SMSCE) are fraught with a plethora of barriers that inhibit and threaten their growth and survival. This research sought to evaluate the critical barriers that affect the growth of SMSCEs in the Ghanaian Construction Industry. The quantitative research method was adopted using a structured questionnaire with variables that were identified through a comprehensive literature review. The survey questionnaire was administered to 400 respondents comprising 250 SMSCEs, 100 Local Authority Engineers, and 50 Consultants to elicit data based on the identified variables. The major findings established by the study as barriers to the growth of SMSCEs in Ghana are largely structured as financial/fiscal barriers, business development barriers, technical/technological barriers, corruption barriers, knowledge management barriers, project acquisition barriers. A guiding framework should be developed based on the barriers identified to aid the growth and survival of SMSCEs in Ghana.
\end{abstract}

\section{Keywords}

Barriers, Business Growth, Business Survival, Developing Countries, Small and Medium Scale Enterprise, SME

\section{Introduction}

The construction industry has unique characteristics that sharply distinguish it from other sectors of the economy in most developing countries. The industry is fragmented, very sensitive to the economic cycles and political environment, and has a significantly high rate of business failures. This situation is not quite dif- 
ferent from the Ghanaian construction industry.

The Ghanaian construction industry is an industry that is increasingly becoming more complex because of growth which is caused by the amount of investment which is made by both public and private in construction projects [1]. The industry is one of the most significant contributors to the economy of Ghana as well as the riskiest businesses in the market [2]. Thus, most Governments and private sector budgets are channeled to infrastructure development. This has been the main motivation for most individuals and organizations to set up construction enterprises that usually fall under small and medium scale categories.

According to Thwala and Phaladi [3], small and medium-scale construction enterprises (SMSCES) play an important role in each country's economy. Small and medium-scale enterprises in Ghana contribute about seventy percent of GDP and form about ninety-two percent of all businesses [4]. SMSCEs recruit substantial numbers of most developing countries' workers. They offer essential needs, livelihoods, and other opportunities for the vulnerable in most developing societies. Despite the invaluable contribution of SMSCEs, they are fraught with numerous barriers that militate against their growth and survival.

Ghana has no regulated bodies that screen people who want to set up their construction businesses, therefore it makes it easy for every individual to start up their own construction companies and many risks are inherited in how the industry operates. The adversative rapport between the key parties of construction projects (owner, consultant, and contractor) is one of the important factors that increase the risk of survival of SMSCEs. Lack of business management skills, high capital cost, lack of transparency is amongst the challenges that hinder the growth of SMSCEs ([2]; and [5], etc.).

Kulemeka et al. [6] and Osei [7] asserted that a large part of the contractors in the construction industry are classified under small and medium scale enterprises. This was corroborated by Amoah [8] who established that SMSCEs in Ghana represent more than Ninety percent of all contractors in the CI. Owing to the critical role SMSCEs play in every economy and the potential to deliver high-level construction projects, it is imperative to explore measures and factors that can guide SMSCEs to survive and grow.

The increasing number of SMSCEs failures and lack of growth makes this study very important. Despite the considerable amount of literature existing on SMEs, few studies have established the barriers to the growth of SMSCEs in Ghana and this is supported by Asante, Kissi, and Badu [2]. Thus, this research sought to validate the existing barriers that impede the growth of SMSCEs in Ghana.

\section{Literature}

\subsection{Small and Medium Scale Construction Enterprises (SMSCEs)}

The definition of the concept of SMSCE differs from one jurisdiction to the other. This was affirmed by Kulemeka et al. [6], where they postulated that the idea of SMSCE has been defined in different forms by scholars from varied jurisdic- 
tions. Currently, a single universally accepted definition of SMSCE does not exist. Most of the definitions established in literature are based on several criteria such as total employees; fixed asset and trade values; the value of capital invested; annual turnover amongst others.

The European Commission [9] defined SMSCE as organizations with not more than two hundred and fifty personnel and revenue of not more than 50 Million Euros each year or a balance sheet accumulation of not more than 43 million Euros each year. It is also defined by Kamal and Flanagan [10] as firms with not more than two hundred (200) permanent staff. SMSCEs are regarded as enterprises that are capable and ready to take up minor and dispersed projects, typically in the countryside [11]. The area of operation of SMSCEs are generally limited due to their nature and usually lack the requisite resources to thrive [2].

The institution mandated to register and categorize works and housing contractors in Ghana is the Ministry of Works and Housing (MWH). A company who duly registers with the Registrar General's Department under Act 179 (1963) of the companies' registration code is then assessed and classified by the MWH based on the equipment the company owns, financial capability, similar works performed over some number of years and technical personnel. The classifications by the $\mathrm{MWH}$ are $\mathrm{D} 1 / \mathrm{K} 1, \mathrm{D} 2 / \mathrm{K} 2, \mathrm{D} 3 / \mathrm{K} 3$, and D4/K4. The "D" category represents building works for class whereas the " $K$ " represents civil works class. This is further categorized into financial classes One (1), Two (2), Three (3), and Four (4). According to Asante et al. [2], D2/K2, D3/K3, and D4/K4 contractors are described as the SMSCEs as they have comparable attributes with regards to their style of management. Every category of these contractors is eligible to carry out projects funded by the government not exceeding US $\$ 500,000.00$, US $\$ 200,000.00$, and US $\$ 75,000.00$, respectively [2]. Thus, the working definition espoused by Asante et al. [2] is adopted for the current study.

\subsection{Barriers to the Growth of SMSCEs}

Earlier studies have discovered that despite the invaluable role SMSCEs play in the construction sector, they are confronted with the risk of collapse with data demonstrating that sixty percent fail in the initial few years [3]. The growth of SMSCEs is typically hampered by numerous barriers that are related to the "regulatory environment, management skills, financial infrastructure, lending capacity, and liquidity and the availability of risk-sharing instruments" [12]. A study conducted by Aigbavboa and Thwala [5] on the "challenges facing black-owned small and medium construction companies: a case study of Nelspruit-Mbombela Municipality, South Africa" established the main challenges facing small-scale contractors. The barriers established by the study were: unreliable cash flow, lack of construction project management skills, improper contract documentation, poor working relationships, inadequate facilities and equipment, communication cultural impact, and inadequate financial management skills. A study conducted in the Gaza Strip to identify the main internal and external challenges of 
small-sized construction firms also revealed that the most important groups of barriers militating against SMSCE growth are Financial barriers, Equipment and materials barriers, Human resources barriers, higher management skills barriers, communication, and work relations barriers, and general business environment barriers [12]. Lack of successful management in the primary phase has been a key reason for business failure for SMSCEs and some crucial characteristics of SMSCEs amongst others are: mostly not registered, function in the informal segment of the economy, and lack formal business structures [3]. Other barriers that militate against the growth of SMSCEs in developing countries are inadequate resources for building the capacity of SMSCEs, inappropriate building procurement arrangements, and insufficient management capacity and resources to arm directors to run their organizations successfully [3]. Several studies such as Rwelamila [13], Miles [14], Croswell and McCutchen [15], Mphahlele [16], and Ofori [17] have all established barriers militating against the growth of SMSCEs, amongst them are lack of finance; lack of credit from suppliers; lack of knowledgeable and experienced workforce; inexperienced pricing, lack of contract documentation skills; lack of mentoring opportunities; and fronting for established contractors; inadequate entrepreneurial skills; no formal training; lack of technical, financial, contractual, and managerial skills; and late payment for work done.

The barriers militating against SMSCEs growth in other developing nations are identical to the situation in Ghana. A study by Donkor [18] on the "determinants of business failure among SMSCEs in Ghana" identified that the topmost barriers are: holdup of projects of former régime, delay in payment by the new government, excessive monetary demands by political and administrative heads, non-payment of fluctuations and interest on a delayed certificate and appointing inexperienced project managers. In terms of Accessing financial capital by SMSCEs, Bondinuba [19] identified unfavorable policy guidelines, insufficient fiscal infrastructure, harsh collateral security conditions, and inadequate institutional capacity of SMSCEs as barriers. Lack of access to information and lack of managerial skills were likewise barriers recognized by the study. Barriers such as lack of technology adoption, insufficient management of contracts, inadequate planning for projects, review of bills of quantities, and lack of transparent and accountable contract tendering procedure were highlighted by Laryea [20] in his study.

A study on the "factors affecting the performance of SMSCEs" revealed barriers inhibiting the performance of SMSCEs as two primary barriers, i.e. monetary policies and managerial barriers [8]. Orhin [21], on the other hand, posited that the barriers against SMSCEs can be categorized into three (3) parts, thus technical barriers, managerial barriers, and financial barriers.

\section{Method}

The type of research adopted is descriptive which tries to highlight barriers to 
the growth of SMSCEs in Ghana. The study design was cross-sectional with a targeted population of SMSCEs under classification D2K2, D3K3, and D4K4, Consultants registered with the Local Authorities (LA)-Metropolitan/Municipalities/District Assemblies and the LA Engineers in Ghana. Overall, 400 respondents were targeted for the study, which involved 100 Local Authority Engineers, 50 Consultants, and 250 SMSCEs.

As the purpose of this research was descriptive, and the research question matched establishing the opinions of respondents on the barriers to the growth of SMSCEs in Ghana, the recommended research strategy was that of the analytical survey. Chileshe and Kikwasi [22] used a similar approach of knowledge, attitudes, and perceptions when investigating the perception of construction professionals on critical success factors appertaining to the deployment of risk assessment and management practices (RAMP) in Tanzania. In all, 400 questionnaires were prepared and distributed to randomly select potential respondents in the various local authorities in the Sixteen (16) Regions of Ghana. Two techniques of data collection were used namely literature review and questionnaire. As regards literature review previous works on the subject matter were reviewed to establish the gap and broaden the knowledge base in the research area. The questionnaire used in this study was designed into three main sections. The first section focused on the background of the respondents and their organizations, section two focused on the barriers to the growth of SMSCEs, while the final section solicited the opinion of respondents on the strategies to mitigate or overcome the barriers to the growth of the SMSCEs in Ghana. The data analysis employed included descriptive statistics and factor analysis. Out of the 400 distributed questionnaires, about 285 questionnaires were collected from the respondents representing a response rate of $71.25 \%$. These comprised of 179 from SMSCEs, 38 from Consultants, and 68 from Local Authority Engineers. The involvement of these groups of respondents is highly significant as they all play a key role in the operation and daily activities of SMSCEs in Ghana. Of the 285 questionnaires, 16 were incomplete resulting in 269 useable for the final data analysis.

The primary focus of this study was to examine the perception of SMSCEs, Consultants, and Local authority engineers on the barriers to the growth of SMSCEs in Ghana. The obtained raw data was input and analyzed using the IBM Statistical package for social sciences (SPSS) computer program version 20.0.0. Three types of analyses were conducted. Review of the literature shows that such approaches have been adopted before in survey-related studies ([23] [24] and [22]). The techniques selected from the aforementioned studies were descriptive statistics, Ranking analysis, and factor analysis.

\section{Results}

\subsection{Background Information of Respondents}

It is worth noting that respondents had enough working experience as $18.6 \%$ have worked for less than five years and 81.4 per cent have worked over six 
years, nonetheless, all the consultants surveyed have over ten years of working experience. On the other hand, $22 \%$ of the SMSCEs surveyed have more than 10 years working experience. Besides, the educational background of the respondents showed that the Consultants and the Local authority Engineers are more educated than SMSCEs. According to Table 1, over Eighty percent of both Consultants and Local Authority Engineers had bachelor degrees, whereas only 28 percent of the SMSCEs hold Bachelors degree. Majority of the SMSCEs holds High school certificate and technician certificates as indicated in Table 1. The result reveals the low educational background of the SMSCEs. This finding affirms that of Asante, Kissi and Badu [2] who in their study also established the educational level of SMSCEs to be low.

\subsection{Validation of Barriers to the Growth of SMSCEs}

The study established the various barriers to the growth of SMSCEs from literature.

Table 1. Background information of respondents.

\begin{tabular}{|c|c|c|c|}
\hline Respondents information & Groups & Categories & Response (\%) \\
\hline \multirow[t]{3}{*}{ Organization belong to } & Consultant & & $13 \%(35)$ \\
\hline & SMSCEs & & $64 \%(173)$ \\
\hline & L/A Engineers & & $33 \%(61)$ \\
\hline \multirow[t]{9}{*}{ Years of experience } & Consultant & Less than 5 years & 0 \\
\hline & & $5-10$ years & 0 \\
\hline & & More than 10 years & $100 \%$ \\
\hline & SMSCEs & Less than 5 years & $18 \%$ \\
\hline & & $5-10$ years & $60 \%$ \\
\hline & & More than 10 years & $22 \%$ \\
\hline & L/A Engineers & Less than 5 years & $32 \%$ \\
\hline & & $5-10$ years & $44 \%$ \\
\hline & & More than 10 years & $24 \%$ \\
\hline \multirow[t]{9}{*}{ Educational qualification } & Consultant & JHS/Middle school & 0 \\
\hline & & SHS/Technical school & $15 \%$ \\
\hline & & Graduate & $85 \%$ \\
\hline & SMSCEs & JHS/Middle school & $14 \%$ \\
\hline & & SHS/Technical school & $58 \%$ \\
\hline & & Graduate & $28 \%$ \\
\hline & L/A Engineers & JHS/Middle school & 0 \\
\hline & & SHS/Technical school & $19 \%$ \\
\hline & & Graduate & $81 \%$ \\
\hline
\end{tabular}


Though some of the studies from the literature were conducted in Ghana, the study sought to validate the barriers to ensure that they are still relevant within the Ghanaian context. From the analysis, any mean score value that was less than 3.0 is deemed to be insignificant for the study because it falls below the neutral rating of 3.0. Standard deviation values of less than 1.0 indicate consistency in agreement among the respondents on the reported level of results [25]. Therefore, to rank the factors fairly, where two or more factors have the same mean score, the one with the lowest standard deviation was assigned the highest importance ranking.

Table 2 summarizes the results of the analysis of the Barriers to the growth of SMSCEs according to the respondents. Examination of Table 2 shows that the mean scores of the thirty-seven barriers to the growth of SMSCEs in Ghana ranged from 4.433 (late payment of work done) to 3.002 (lack of innovation) with an average score of 3.845. Further examination of Table 2 also shows that all the Barriers were significant as their mean score exceeded the set benchmark of 3.00 as previously stipulated. Based on the overall mean score, the five barriers to the growth of SMSCEs in Ghana are identified as highly ranked are: Late payment for work done (4.433); Political interference in the award of contract (4.402); Harsh collateral security condition (4.388); High-interest rates (4.363); and Lack of entrepreneurial skills (4.302). Since all the 37 barriers were significant based on the responses of the respondents, they were all considered for the factor analysis.

\subsection{Factor Analysis of the Barriers to the Growth of SMSCEs}

In the second instance, factor analysis (FA) was utilized to find groups of related constructs. Asante, Kissi, and Badu [2] emphasized that factor analysis is very helpful for finding groups of related variables and thus is ideal for reducing a large number of variables into a more easily comprehensible structure. The fundamental function of FA is to investigate the underlying variance of a set of correlation coefficients, thus, compressing data contained in original variables into a smaller set of factors with minimum data loss [26]. To find out if the samples are sufficient for Factor Analysis, Kaiser-Meyer-Olkin (KMO) measure of sampling adequacy, and Bartlett's test of sphericity were conducted.

The KMO examines sample adequacy, whilst Bartlett's test examines the null hypothesis if the original correlation matrix is an identity matrix. A sample is adequate if the value of KMO is not less than 0.5 [25]. From Table 3, the KMO value obtained is 0.722 , whereas the $\chi^{2}$ value obtained by Bartlett's test of sphericity is 2822.243 with a significant value of 0.000 indicating that the null hypothesis of the correlation matrix being identical is rejected; hence, there exist significant correlations in the data set, that is, appropriate for factor analysis. Thus, the samples satisfy the condition for factor analysis (Table 3 ).

After satisfying the necessary condition for factor analysis, the eigenvalue and factor loadings were set at the conventional values of 1.00 and 0.50 , respectively 
Table 2. Barriers to SMSCEs growth.

Barriers to SMSCE Growth

Late payment for work done

Political interference in the award of contract

Harsh collateral security condition

High interest rates

Lack of entrepreneurial skills

Unreliable cash flow

Lack of credit from suppliers

Lack of financial management skills

Lack of local SME development policy

Lack of transparency in procurement process

Ineffective human resource management

Competition with large firms

Inexperienced pricing

Improper contract documentation

Lack of industry knowledge

Poor brand management

Demand of bribe

High guarantee/bond requirement

High taxes

Non-payment of fluctuation/interests on delayed certificate

Lack of technology adoption

Poor marketing skills

Lack of business advisory support

Lack of technical skills

Lack of contract management skills

Lack of construction project management skills

Poor working relationships

Lack of knowledgeable and experienced workforce

No formal training

Lack of contract documentation skills

Holdup of projects of former régime

Lack of access to information

Lack of mentoring opportunities

Lack of accessing equipment

Complex tendering procedure

Unstable inflation

Lack of innovation

Mean Score SD Ranking

4.433

0.8414

$\begin{array}{lll}4.402 & 0.7457 \quad 2\end{array}$

$\begin{array}{lll}4.388 & 0.8544 \quad 3\end{array}$

$4.363 \quad 0.7545 \quad 4$

$\begin{array}{lll}4.302 & 0.7834 \quad 5\end{array}$

$\begin{array}{lll}4.268 & 0.7874 \quad 6\end{array}$

$\begin{array}{lll}4.245 & 0.8979 \quad 7\end{array}$

$\begin{array}{lll}4.229 & 0.9225 \quad 8\end{array}$

$\begin{array}{lll}4.212 & 0.8092 \quad 9\end{array}$

$4.201 \quad 1.0102 \quad 10$

$\begin{array}{lll}4.186 & 0.8294 \quad 11\end{array}$

$\begin{array}{lll}4.155 & 1.0143 \quad 12\end{array}$

$\begin{array}{lll}4.098 & 0.8843 \quad 13\end{array}$

$4.024 \quad 0.9076 \quad 14$

$\begin{array}{lll}4.011 & 1.1234 & 15\end{array}$

$3.987 \quad 0.8295 \quad 16$

$\begin{array}{lll}3.945 & 0.8254 & 17\end{array}$

$3.933 \quad 0.8976 \quad 18$

$\begin{array}{lll}3.904 & 0.9904 \quad 19\end{array}$

$\begin{array}{lll}3.889 & 0.8624 & 20\end{array}$

$\begin{array}{lll}3.856 & 0.7057 & 21\end{array}$

$\begin{array}{lll}3.834 & 0.8444 \quad 22\end{array}$

$\begin{array}{lll}3.811 & 0.7568 \quad 23\end{array}$

$3.743 \quad 0.9654 \quad 24$

$\begin{array}{lll}3.678 & 0.8003 \quad 25\end{array}$

$\begin{array}{lll}3.603 & 0.8599 \quad 26\end{array}$

$\begin{array}{lll}3.564 & 0.9224 & 27\end{array}$

$\begin{array}{lll}3.523 & 1.0092 \quad 28\end{array}$

$\begin{array}{lll}3.512 & 1.0182 & 29\end{array}$

$3.487 \quad 0.9394 \quad 30$

$3.421 \quad 1.0829 \quad 31$

$3.402 \quad 0.8714 \quad 32$

$\begin{array}{lll}3.334 & 0.8906 \quad 33\end{array}$

$3.112 \quad 1.1211 \quad 34$

$\begin{array}{lll}3.104 & 0.8583 \quad 35\end{array}$

$3.099 \quad 0.8213 \quad 36$

$3.002 \quad 0.9541 \quad 37$ 
Table 3. Kaiser-Meyer-Olkin and Bartlett's test of sphericity。

\begin{tabular}{ll}
\hline Kaiser-Meyer-Olkin measure of sampling adequacy & 0.722 \\
Bartlett's test of sphericity Approx. $\chi^{2}$ & 2822.24 \\
Df & 164 \\
Sig. & 0.000 \\
\hline
\end{tabular}

Table 4. Total variance of the Barriers to the Growth of SMSCEs.

\begin{tabular}{|c|c|c|c|c|c|c|c|c|c|}
\hline Component & Total & $\begin{array}{c}\text { Initial eigen } \\
\text { values \% of } \\
\text { Variance }\end{array}$ & $\begin{array}{c}\text { Cumulative } \\
\%\end{array}$ & Total & $\begin{array}{c}\text { Extraction sums } \\
\text { of squared } \\
\text { loadings \% of } \\
\text { Variance }\end{array}$ & $\begin{array}{c}\text { Cumulative } \\
\%\end{array}$ & Total & $\begin{array}{l}\text { Rotation sums } \\
\text { of squared } \\
\text { loadings \% of } \\
\text { variance }\end{array}$ & $\begin{array}{c}\text { Cumulative } \\
\%\end{array}$ \\
\hline 1 & 3.675 & 19.045 & 19.045 & 3.675 & 19.045 & 19.045 & 2.912 & 13.993 & 13.993 \\
\hline 2 & 2.824 & 14.889 & 33.934 & 2.824 & 14.889 & 33.934 & 2.882 & 13.554 & 27.547 \\
\hline 3 & 2.783 & 12.554 & 46.488 & 2.783 & 12.554 & 46.488 & 2.744 & 12.384 & 39.931 \\
\hline 4 & 2.143 & 10.446 & 56.934 & 2.143 & 10.446 & 56.934 & 2.034 & 10.262 & 50.193 \\
\hline 5 & 1.825 & 8.296 & 65.230 & 1.825 & 8.296 & 65.230 & 1.928 & 9.586 & 59.779 \\
\hline 6 & 1.432 & 6.421 & 71.651 & 1.432 & 6.421 & 71.651 & 1.867 & 9.432 & 69.211 \\
\hline
\end{tabular}

and six components were extracted using the latent root criterion (Table 4). Component 1 accounted for 19.045 percent of the total variance and component 2 accounted for 14.889 percent of the total variance. The components 3 and 4 accounted for 12.554 percent and 10.446 percent total variances, respectively, whilst component 5 accounted for 8.296 percent and component 6 accounted for 6.421 percent. The cumulative variance for six extracted components is 71.651 percent. Based on the careful assessment of the inherent relationships among the variables under each component, the following theme was inferred to represent the underlying dimensions of the components. Component 1: Financial/Fiscal Barriers; component 2: Business Development Barriers; component 3: Technical/Technology Barriers; component 4: Corruption Barriers; component 5: Knowledge Management Barriers; and component 6: Project Acquisition Barriers. The data were further subjected to principal component analysis with varimax rotation. The factor loading for the varimax orthogonal rotation represents both how the variable is weighted for each other and the correlation between the variables and the factors.

Factor Analysis values are better interpreted through rotation and maximize the loading of each variable on one of the extracted factors whilst minimizing the loading on all other factors [25]. A variable that emerges to have the highest loading in one component belongs to that component. According to Field [25] rotation works through changing the absolute values of the variables whilst keeping their differential values constant. 


\section{Discussions}

Table 4 shows the factor loadings of six components. Through careful examination of the components, the subsequent interpretation was inferred to represent the underlying factors of the components. These are as follows:

1) Component 1: Financial/Fiscal Barriers.

2) Component 2: Business Development Barriers.

3) Component 3: Technical/ Technological Barriers.

4) Component 4: Corruption Barriers.

5) Component 5: Knowledge Management Barriers.

6) Component 6: Project Acquisition Barriers.

\subsection{Component 1: Financial/Fiscal Barriers}

The first component explains the variables unreliable cash flow (0.932), lack of credit from suppliers (0.918), late payment for work done (0.892), non-payment of fluctuation/interests on a delayed certificate (0.852), high taxes (0.788), high-interest rates (0.743) and unstable inflation (0.590) and accounted for 19.045 percent of the total variance. The component was labeled financial/fiscal barriers as each of the defined variables relates to finance and fiscal matters and serves as a barrier to SMSCE growth. This component may not be surprising as fiscal and issues of finance are crucial to any business's existence. Evidence provided by Bonger and Chileshe [27] strongly indicates that countries with consistently high economic growth rates often have their government investing in their economy to offer sufficient motivations and regulations for private investment. Given the significant impact of fiscal and monetary strategy on the corporate climate, the government must handle it judiciously, as the behavior of governments has a serious influence on entrepreneurial growth [28]. Offering a favorable macroeconomic climate lets SMEs grow their businesses. The government leveraging fiscal and monetary policy tools can establish a favorable business climate for SMSCE growth. Extra monetary strategies that may pose barriers to SMSCE commercial operational setting are higher interest rates and higher inflation. An argument is made for lowering higher interest rates and higher inflation to promote SME growth. Most SMEs need financing from banking firms, so interest rates are a key factor [29]. On the contrary, inflation affects all manner of businesses, but customers of SMEs suffer as it raises the cost of products and reduces their disposable cash. Inflation leads to increased spending, which decreases SME revenues and diffuses investment to ensure business development and success.

In terms of financial barriers, timely payments are essential to any business's cash flow, particularly SMSCEs [2]. However, insufficient funds are amongst the primary reasons for contractors' economic problems [30]. Also, some of the primary reasons for contractors' pecuniary problems are late compensation, poor revenue margins, and insufficient funding. Luger [31] postulated that Payment delays generally related to public sector contracts are the cause of many 
construction firms' business failure. Ease of access to credit and funding is the biggest problem for SMSCEs [32]. SMSCEs face loan access problems due to its exceptional attributes. They are therefore unable to bid for loans with large companies since they are deemed too volatile to obtain loans. Besides, SMEs cannot meet financial institutions' collateral criteria. Reviewing collateral criteria will greatly support experienced SMEs.

\subsection{Component 2: Business Development Barriers}

The second component explains the variables: lack of mentoring opportunities (0.886), lack of entrepreneurial skills (0.768), lack of local SME development policy (0.707), and lack of business advisory support (0.583) and also accounted for 14.889 percent of the total variance. The component was named business development barriers because each of the variables observed serves as a barrier to the business development aspect of SMSCE growth. Successful business support structures are required to improve SMEs' competitiveness and productivity [2]. External business support has a positive influence on the growth of SMSCEs [33]. Business development barriers have now become critical to SMSCE growth. Business advisory support, mentoring opportunities, local development policies offer businesses with a broad variety of non-financial resources to help them work effectively and expand their business [34]. Additionally, evidence provided by Lambrecht and Pirnay [35] indicates the positive effect of using external guidance and further backing resources on the probability of survival of new enterprises. In developing countries, however, the business knowledge needed to help SMEs grow is rare. Market knowledge of business opportunities, consumer patterns, organizational methods, etc., is not effectively transmitted to SMEs in most developing countries, hampering growth [36].

\subsection{Component 3: Technical/Technology Barriers}

The third component explains the variables lack of construction project management skills (0.898), improper contract documentation (0.862), lack of knowledgeable and experienced workforce (0.789), lack of contract documentation skills (0.742), lack of technical skills (0.691), lack of contract management skills (0.645), lack of technology adoption (0.602), lack of access to information (0.585), and lack of accessing equipment (0.505) and accounted for 12.554 percent of the total variance and was subsequently named technical/technology barriers. Asante et al. [2] indicated the advantages of technical capabilities to SMSCEs, but tax cuts can ease business working capital constraints and raise market demand [37]. Lack of equipment and outdated technologies are amongst the barriers to SME growth. Technology offers enterprises modern resources to increase their productivity. SMSCEs that use technologies in their activities are expected to overtake others who do not utilize technology. Most SMSCEs, nevertheless, lack awareness and access to the innovations currently pushing the sector. SMSCEs are presently not doing well in the implementation of modern technologies. In 
third world nations where projects require moderately innovative technologies, SMSCEs may be unable to execute them [38]. Besides, other unique services and expertise are needed by business owners in the industry to succeed. Consequently, besides financial assistance, Hussain [39] stressed the value of skilled training. Technical assistance helps foster economic growth by exchanging concepts, expertise, activities, technology, or skills [40]. In the construction industry, most current works need strong technical skills in project management, contract documentation, and other technical skills to be able to execute projects effectively, but most SMSCEs cannot provide these skills. Therefore, SMSCEs must improve their technical and technological ability and skills in the construction industry to allow them to effectively manage projects.

\subsection{Component 4: Corruption Barriers}

The following factors loaded onto this principal component: lack of transparency in the procurement process (0.786), political interference in the award of contract (0.722), and demand of bribe (0.503) (Table 5). Corruption affects all types of enterprises, but the impact is greatest among SMEs [2]. SMEs face corruption when working with government officials at all levels. They also face demands for extra compensation for services they are entitled to. The construction industry's corruption is not a recent phenomenon [2]. This may be due to the industry's market climate. The vast proportion of the work is gotten by competitive bidding. Thus, there is a higher propensity for people to manipulate the process to their advantage. In the construction industry in Ghana, the contractor's willingness to pay a kickback to the participants concerned determines the contractor's job [20] combined with undue interference by a variety of politicians who feel they possess the power to interfere in procurement processes, leading to unpredictable procurement results [41]. Corruption can inhibit rapid economic growth overtly or covertly. Corruption generates volatility in handling SMEs by reducing their profit margins. When companies fail to engage in unethical activity, they lose out on contracts. Corruption is amongst the key barriers to the growth of small and medium scale but considering the significance of SMEs to the economic system and their business insecurity, any misconduct that attempts to distress the capability of SMEs to participate equally in contracts must be seen as an economic growth problem [42].

\subsection{Component 5: Knowledge Management Barriers}

The following factors emerged: improper human resource management (0.823), poor working relationships (0.766), no formal training (0.724), lack of financial management skills (0.686), poor marketing skills (0.655), lack of industry knowledge (0.601), lack of innovation (0.582), and poor brand management (0.522) (as shown in Table 5). The numerous factors loaded on this component directly or indirectly affect Ghana's SMSCE growth. Knowledge management, if properly applied, contributes significantly to SME growth. This could work well 
Table 5. Rotated component matrix of barriers to the growth of SMSCEs.

\begin{tabular}{|c|c|c|c|c|c|c|c|}
\hline \multirow{2}{*}{\multicolumn{2}{|c|}{ No. Barriers against SMSCE Growth }} & \multicolumn{6}{|c|}{ Component } \\
\hline & & 1 & 2 & 3 & 4 & 5 & 6 \\
\hline 1 & Unreliable cash flow & 0.932 & & & & & \\
\hline 2 & Lack of credit from suppliers & 0.918 & & & & & \\
\hline 3 & Late payment for work done & 0.892 & & & & & \\
\hline 4 & Non-payment of fluctuation/interests on delayed certificate & 0.852 & & & & & \\
\hline 5 & High taxes & 0.788 & & & & & \\
\hline 6 & High interest rates & 0.743 & & & & & \\
\hline 7 & Unstable inflation & 0.590 & & & & & \\
\hline 8 & Lack of mentoring opportunities & & 0.886 & & & & \\
\hline 9 & Lack of entrepreneurial skills & & 0.768 & & & & \\
\hline 10 & Lack of local SME development policy & & 0.707 & & & & \\
\hline 11 & Lack of business advisory support & & 0.583 & & & & \\
\hline 12 & Lack of construction project management skills & & & 0.898 & & & \\
\hline 13 & Improper contract documentation & & & 0.862 & & & \\
\hline 14 & Lack of knowledgeable and experienced workforce & & & 0.789 & & & \\
\hline 15 & Lack of contract documentation skills & & & 0.742 & & & \\
\hline 16 & Lack of technical skills & & & 0.691 & & & \\
\hline 17 & Lack of contract management skills & & & 0.645 & & & \\
\hline 18 & Lack of technology adoption & & & 0.602 & & & \\
\hline 19 & Lack of access to information & & & 0.585 & & & \\
\hline 20 & Lack of accessing equipment & & & 0.505 & & & \\
\hline 21 & Lack of transparency in procurement process & & & & 0.786 & & \\
\hline 22 & Political interference in the award of contract & & & & 0.722 & & \\
\hline 23 & Demand of bribe & & & & 0.503 & & \\
\hline 24 & Improper human resource management & & & & & 0.828 & \\
\hline 25 & Poor working relationships & & & & & 0.766 & \\
\hline 26 & No formal training & & & & & 0.724 & \\
\hline 27 & Lack of financial management skills & & & & & 0.686 & \\
\hline 28 & Poor marketing skills & & & & & 0.655 & \\
\hline 29 & Lack of industry knowledge & & & & & 0.601 & \\
\hline 30 & Lack of innovation & & & & & 0.582 & \\
\hline 31 & Poor brand management & & & & & 0.522 & \\
\hline 32 & Inexperienced pricing & & & & & & 0.767 \\
\hline 33 & Holdup of projects of former régime & & & & & & 0.711 \\
\hline 34 & Harsh collateral security condition & & & & & & 0.682 \\
\hline 35 & Competition with large firms & & & & & & 0.642 \\
\hline 36 & High guarantee/bond requirement & & & & & & 0.586 \\
\hline 37 & Complex tendering procedure & & & & & & 0.523 \\
\hline
\end{tabular}


for SMEs if correctly implemented and used, providing them with improved service quality, higher performance, and lower costs [43]. Other organizational characteristics that have a positive impact on SME performance include handling human resources, strong working relationships, financial management skills, marketing skills, and networked information management [44]. Human resource management is essential to ensuring that an SME has the potential to expand because the corporate knowledge base is human [45]. Therefore, the main factors in SME HR management are organizational learning through routine and formal training (including owner/manager) and recruiting [44]. Another main feature of knowledge management is the extent of its dissemination in corporate networks ensuring that participants share expertise [45]. This can open new opportunities and creativity, but also to improved market efficiency [46]. The significance here is not the actual geographical position but the fact that the network constantly spreads information [46]. Therefore, Valkokari and Helander [45] indicated that SMEs ought to make a deliberate effort to manage the distribution of information within the firm but also its immediate network. This includes using technical solutions but should be done so that SMEs' informality is not lost.

\subsection{Component 6: Project Acquisition Barriers}

The following factors loaded onto this principal component: inexperienced pricing (0.767), holdup of projects of former régime (0.711), harsh collateral security condition (0.682), competition with large firms (0.642), high guarantee/bond requirement (0.586), and complex tendering procedure (0.523) (as shown in Table 5). The multiple factors loaded onto this main component contend the barriers to SMSCE growth in project acquisition and continuous workflow has been a key barrier for SMSCEs in the industry. Contractors complained that contracting takes up to half a year in some situations [20]. Any of these obstacles might account for the small business's inability to get work. For example, SMSCE's inability to meet bond conditions prohibited many from contract securing [47]. Asante et al. [2] asserted that the key source for most SMSCEs to procure their work is often working subcontractors for large-scale contractors to help complete projects. The implication is that, in the absence of job opportunities, most SMSCEs will be deprived of the income and development required in the construction business climate in their track record and creditworthiness. Reinforced by the fact that job opportunities through the subcontracting agreement between large enterprises and SMEs promote technology transfer and ultimately improve SME capacities [48].

\section{Conclusion}

SMSCE capacity in developing economies remains imperative, particularly as these SMEs function as an economic foundation globally. Besides that, it has been reported that SMEs in advanced nations is the growth driver for numerous 
economic revolutions. The present study showed major barriers to SMSCE growth in Ghana. These are largely structured as financial/fiscal barriers, business development barriers, technical/technological barriers, corruption barriers, knowledge management barriers, project acquisition barriers. Also, the government needs to make deliberate efforts to deal with the problems posed in this article to promote the sustained growth of SMSCEs in Ghana. Additional research is required to determine the effects of various barriers to SMSCE growth in Ghana. Besides that, Ghana should explore strategies and guidelines for enhancing the growth of SMSCEs. Lastly, local policies should be deliberately developed to promote SMSCEs' rapid and sustained growth in Ghana.

\section{Conflicts of Interest}

The authors declare no conflicts of interest regarding the publication of this paper.

\section{References}

[1] Enshassi, A., Al-Hallaq, K. and Mohamed, S. (2006) Causes of Contractor's Business Failure in Developing Countries: The Case of Palestine. Journal of Construction in Developing Countries, 11, 1-14.

[2] Asante, J., Kissi, E. and Badu, E. (2018) Factorial Analysis of Capacity-Building Needs of Small- and Medium-Scale Building Contractors in Developing Countries: Ghana as a Case Study. Benchmarking: An International Journal, 25, 357-372. https://doi.org/10.1108/BIJ-07-2016-0117

[3] Thwala, W.D. and Phaladi, J.P. (2009) An Exploratory Study of Problems Facing Small Contractors in the North-West Province of South Africa. African Journal of Business Management, 3, 533-539.

[4] Ahiawodzi, A.K. and Adade, T.C. (2012) Access to Credit and Growth of Small and Medium Scale Enterprises in the Ho Municipality of Ghana. British Journal of Economics, Finance and Management Sciences, 6, 34-51.

[5] Aigbavboa, C. and Thwala, W.D. (2014) Challenges Facing Black Owned Small and Medium Construction Companies: A Case Study of Nelspruit-Mbombela Municipality, South Africa. Journal of Economics and Behavioral Studies, 6, 771-778. https://doi.org/10.22610/jebs.v6i10.536

[6] Kulemeka, P.J., Kululanga, G. and Morton, D. (2015) Critical Factors Inhibiting Performance of Small- and Medium-Scale Contractors in Sub-Saharan Region: A Case for Malawi, Journal of Construction Engineering, 2015, Article ID: 927614. https://doi.org/10.1155/2015/927614

[7] Osei, V. (2013) The Construction Industry and Its Linkages to the Ghanaian Economy-Polices to Improve the Sector's Performance. International Journal of Development and Economic Sustainability, 1, 56-72.

[8] Amoah, P., Ahadzie, D.K. and Ayirebi, D. (2011) Factors Affecting Construction Performance in Ghana: Perspective of Small-Scale Building Contractors. The Ghana Surveyor, 4, 41-48.

[9] European Commission (2012) SME Definition-Small and Medium Sized Enterprises (SME) -Enterprise and Industry.

http://ec.europa.eu/enterprise/policies/sme/facts-figures-analysis/sme-definition/in 
deen.htm

[10] Kamal, E.M. and Flanagan, R. (2014) Model of Absorptive Capacity and Implementation of New Technology for Rural Construction SMEs, Australasian Journal of Construction Economics and Building Conference Series, 2, 19-26. https://doi.org/10.5130/ajceb-cs.v2i2.3885

[11] United Nation Conference on Human Settlements (UNCHS) (1996) Policies and Measures for Small Scale-Contractors Development in the Construction Industry. UN-HABITAT, Nairobi.

[12] Tayeh, B.A., Alaloul, W.S. and Muhaisen, W.B. (2019) Challenges Facing Small-Sized Construction Firms in the Gaza Strip. The Open Civil Engineering Journal, 13, 51-57. https://doi.org/10.2174/1874149501913010051

[13] Radzeviciene, D. (2008) Developing Small and Medium Enterprises Using Knowledge Management Frameworks: A Case Study in Lithuania. Aslib Proceedings. New Information Perspectives, 60, 672-685. https://doi.org/10.1108/00012530810924339

[14] Miles, D. (1980) Guidelines for the Development of Small Construction. ITDG Publishing, Rugby.

[15] Croswell, J. and McCutcheon, T. (2001) Small Contractor Development and Employment: A Brief Survey of Sub-Saharan Experiences in Relation to Civil Construction. Proceedings of the First International Conference in Employment Creation in Development, Johannesburg, 2-5 April 2001.

[16] Mphahlele, G. (2001) Contractor Development in South Africa. Conference on Developing the Construction Industries in Southern Africa. DPW.

[17] Ofori, G. (1991) Programmes for Improving the Performance of Contracting Firms in Developing Countries. Journal of Construction Management and Economics, 9 , 19-38. https://doi.org/10.1080/01446199100000003

[18] Donkor, S. (2011) Determinants of Business Failure: The Perspective of SMEs Building Contractors in the Ghanaian Construction Industry. Master's Thesis, Kwame Nkrumah University of Science and Technology, Kumasi.

[19] Bondinuba, F.K. (2012) Exploring the Challenges and Barriers in Accessing Financial Facilities by Small and Medium Construction Firms in Ghana. Civil and Environmental Research, 2, 25-35.

[20] Laryea, S. (2010) Challenges and Opportunities Facing Contractors in Ghana. Proceedings West Africa Built Environment Research (WABER) Conference, Accra, 27-28 July 2010, 215-226.

[21] Orhin, T.K. (2014) Developing a Framework for Training to Build the Capacity of Small-Scale Local Contractors in Ghana Dept. of Building Technology. Unpublished Master's Thesis, Kwame Nkrumah University of Science and Technology, Ghana.

[22] Chileshe, N. and Kikwasi, G.J. (2014) Critical Success Factors for Implementation of Risk Assessment and Management Practices within the Tanzanian Construction Industry. Engineering Construction \& Architectural Management, 21, 291-319. https://doi.org/10.1108/ECAM-01-2013-0001

[23] Yuan, H. and Wang, J. (2011) Factors Affecting Contractors' Risk Attitudes in Construction Projects: Case Study from China. International Journal of Project Management, 29, 209-219. https://doi.org/10.1016/j.ijproman.2010.02.006

[24] Famakin, I.O., Aje, I.O. and Ogunsemi, D.R. (2012) Assessment of Success Factors for Joint Venture Construction Projects in Nigeria. Journal of Financial Management of Property and Construction, 17, 153-165. 
https://doi.org/10.1108/13664381211246606

[25] Field, A. (2005) Discovering Statistics Using SPSS for Windows. Sage Publications, London.

[26] Syed, M.Q. and Mohammed, N.A. (2009) Constraints to SMEs: A Rotated Factor Analysis Approach. South Asian Studies, 24, 334-350.

[27] Bonger, T. and Chileshe, C. (2013) The State of Business Practices and the Impact of BDS on MSMEs ICBE-RF. Research Report No. 76/13, IDRC, Dakar.

[28] Mazzucato, M. (2013) The Entrepreneurial State: Debunking Public vs Private Sector Myths. Anthem Press, London.

[29] Cant, M.C. and Wiid, J.A. (2013) Establishing the Challenges Affecting South African SMEs. International Business \& Economics Research Journal, 12, 707-716. https://doi.org/10.19030/iber.v12i6.7869

[30] Thornton, G. (2007) Surety Credit Survey for Construction Contractors: The Bond Producer's Perspective. https://www.grantthornton.com/staticfiles/GTCom/files/Industries/ConstructionRe alEstateAndHospitality/2007_surety_survey_new.pdf

[31] Luger, L. (1997) Report on the Small and Medium Enterprise International Study Tour: Singapore, Malaysia and Bangladesh.

[32] Nkuah, J.K., Tanyeh, J.P. and Gaeten, K. (2013) Financing Small and Medium Enterprises (SMEs) in Ghana: Challenges and Determinants in Accessing Bank Credit. International Journal of Research in Social Sciences, 2, 12-25.

[33] Cumming, D. and Fischer, E. (2010) Assessing the Impact of Publicly Funded Business Advisory Services on Entrepreneurial Outcomes. Osgoode-York Working Paper Series in Policy Research, 2, 1-37.

[34] Ellahi, N., Bukhari, T.A. and Naeem, M. (2010) Role of Islamic Modes of Financing for Growth of SMEs: A Case Study of Islamabad City. International Journal of Academic Research, 2, 161-171.

[35] Lambrecht, J. and Pirnay, F. (2005) An Evaluation of Public Support Measures for Private External Consultancies to SMEs in the Walloon Region of Belgium. Entrepreneurship \& Regional Development, 17, 89-108. https://doi.org/10.1080/0898562042000338598

[36] Okello-Obura, C., Minishi-Majanja, M.K., Cloete, L.M. and Ikoja-Odongo, J.R. (2008) Business Activities and Information Needs of SMEs in Northern Uganda: Prerequisites for an Information System. Library Management, 29, 367-391. https://doi.org/10.1108/01435120810869138

[37] Vandenberg, P. (2009) Micro, Small and Medium-Sized Enterprises and the Global Economic Crisis Impacts and Policy Responses. International Labour Organization, Geneva.

[38] Ofori, G. (1990) The Construction Industry: Aspects of Its Management and Economics. Singapore University Press, Singapore.

[39] Hussain, M.N. (2000) Linkages between SMEs and Large Industries for Increased Markets and Trade: An African Perspective. Economic Research Papers No. 53, The African Development Bank, Abidjan.

[40] World Bank (1991) Managing Technical Assistance in the 1990s: Report of the Technical Assistance Review Task Force. World Bank, Washington DC.

[41] World Bank (2004) Main Findings and Recommendations. World Bank, Washington DC. 
http://documents.worldbank.org/curated/en/2004/06/5841742/uganda-country-pro curement-assessment-report-cpar-vol-2-3-main-findings-recommendations

[42] Association of Chartered Certified Accountants (ACCA) (2007) Bribery and Corruption: The Impact on UK SMEs. https://www.accaglobal.com

[43] Metaxiotis, K. (2011) Introducing ERPs to SMEs: A Two-Dimensional Review and Analysis. The Business Review, 17, 83-90.

[44] Lacoursiere, R., Fabi, B. and Raymond, L. (2008) Configuring and Contextualizing HR Systems: An Empirical Study of Manufacturing SMEs. Management Revue, 19, 106-125. https://doi.org/10.5771/0935-9915-2008-1-2-106

[45] Valkokari, K. and Helander, N. (2007) Critical Success Factors for Implementing Knowledge Management in Small and Medium Enterprises. Institutional Management and Data Systems, 105, 261-279. https://doi.org/10.1108/02635570510590101

[46] Boschma, R.A. (2007) Knowledge Networks and Innovative Performance in an Industrial District: The Case of a Footwear District in the South of Italy. Industry and Innovation, 14, 177-199. https://doi.org/10.1080/13662710701253441

[47] Thwala, W.D. and Mvubu, M. (2008) Current Challenges and Problems Facing Small and Medium Scale Contractors in Swaziland. African Journal of Business Management, 2, 93-98.

[48] Yong, F. (2011) "Learning by Sub-Contracting" or "Self-Selection" as a TNCs Local Sub-Contractor: Micro-Level Evidence from China. Institute of Developing Economies, Japan External Trade Organisation, Mihamaku. 